\title{
A critical analysis and optimization of the testing \& validation activities inside an automotive partsfactory
}

\author{
Lucian-PetruPăvăloi ${ }^{*}{ }^{* 1}$ and FlorinNegoescu ${ }^{2}$ \\ ${ }^{1}$ Gheorghe Asachi Technical University of Iași,Faculty of Machine Manufacturing \& Industrial \\ Mnagement,Blv. ProfesorDimitrieMangeron 67, Iași 700050, România \\ ${ }^{2}$ Gheorghe Asachi Technical University of Iași,Faculty of Machine Manufacturing \& Industrial \\ Management, Blv. ProfesorDimitrieMangeron 67, Iași 700050, România
}

\begin{abstract}
The scope of this paper is to critically analyze and optimize the solutions available from a Lean Management point of view, for the testing $\&$ validation department of an automotive factory. The paper will start with an analysis of the basic principles of Lean Management and how this can be applied successfully, followed by a Value Stream Mapping critical analysis of the status at a given time and the action taken with the scope of optimizing the process, concluding with an updated analysis of the new Value Steam Map, showcasing the advantages and the improvements achieved.
\end{abstract}

\section{Introduction into Lean Management}

\subsection{Lean Manufacturing}

Lean Manufacturing is currently the most important management method for production companies. The method is used in conjunction with the quality tool called "6 sigma", is based on the Toyota production system and was adopted in 1995, for Western companies, by Jim Womack and Dan Jones[4], two university professors from the US and UK, who led an evaluation study in the automotive industry and concluded that Toyota outperforms other competitors in the market in terms of performance: productivity, cost, quality, and delivery. After a thorough analysis, they realized that all the tools and techniques used by Toyota are universal. Even in industries other than the automotive industry, this strategy ensures the most spectacular increase in efficiency and competitiveness.

Lean manufacturing is a systematic approach to identifying and eliminating waste (nonvalue-added activities) through continuous improvement by flowing the product at the customer's pull in pursuit of perfection. Lean identified eight wastes in the manufacturing viz. overproduction, waiting, transportation, over-processing or incorrect processing, excess inventory, unnecessary movement, defects, and unused employee creativity. The system focused on identifying significant waste sources and using tools like JIT, production

Correspondingauthor: pavaloilucian@gmail.com 
smoothing, and others to eliminate the waste. Lean manufacturing uses various tools like value stream mapping (VSM), 5S, visual management, Kanban, Kaizen, line balancing, cellular manufacturing, just in time (JIT), single minute exchange of dies (SMED), standardized work, etc. to eliminate these wastes and achieve better productivity, smooth flow, reduction in cycle time and many benefits.Every industry wants to improve its product and standardize it by removing all the non-value-adding processes. Lean manufacturing techniques can be effectively used to remove the waste from the product's process and improvement [1].

Other important papers [2] [3] [4] have applied the same analysis and lean principles with the same goal in mind, to optimize and remove waste in any of its forms (as described by Jim Womack and Dan Jones.

\subsection{The benefits of implementing the Lean principles}

In their research [4] "From Lean Production to the Lean Enterprise (Harvard Business Review, March-April 1994)", the two university professors, Jim Womack, and Dan Jones have observed and defined the most notable benefits of Lean implementation, as follows:

- The hours of human effort in the factory - halved;

- The defects in finished products - halved;

- The design effort hours - decrease to one third;

- The workspace for the same production - halves;

- The stocks under manufacture - decrease to one-tenth;

In essence, Lean means to produce cheaper, better, at the time rate requested by the customer and with the flexibility for the variations in the demand. It also means producing more with less consumption: space, stocks, people, time. Continuous development methodologies such as Lean Manufacturing techniques and tools, Six Sigma, and Scientific Management underlie the management philosophy of Operational Excellence. This is a company management system in which each of the employees can see the flow of value to the customer and is directly involved in repairing it before it is interrupted.

\subsection{The Lean Principles}

In their studies Jim Womack and Dan Jones[4], defined the 5 principles that characterize a Lean enterprise:

-Specifies the value from the end customer's point of view;

- Identifies the steps in the value stream for each family of products and eliminate waste (Muda)[10];

- Make the product flow;

- So that the customer can shoot;

- Pursuing perfection through continuous improvement;

The fundamental philosophy in Lean is the definition of Value from the point of view of the customer (consumer). All those activities that do not add value in the eyes of the client (but only generate costs) are identified as Waste (Muda).

Starting with Albert Einstein's quote, which says that "Not everything that can be quantified matters, just as not everything that matters can be quantified." we can begin to understand that a system of LEAN indicators allows decisions to be made based on the analysis of data and information, respectively objective evidence, obtained by observation, measurement, testing, other appropriate methods of quantification and estimation.

LEAN indicators must be chosen carefully because they must be few, expressed in physical quantities that are easy to understand, quantify and measure (daily, weekly, 
monthly, annually), process-oriented, and intended to be used by staff in production and management.

There are four key elements in the production environment: productivity, quality, safety, and costs [10]. Typical indicators for Lean production relate to these four elements and consist in determining the time from receipt to dispatch of the order, stock rotation, duration of obtaining the first product of a certain kind, the percentage of deliveries on time, overall equipment efficiency (OEE).

\section{The Value stream map (VSM)}

In Lean, this optimization can be achieved by applying the tool known as Value Stream Design - "Value Flow Map" [8]. The author Klaus Erlach has detailed the improvements that the Value Steam Map is bringing to Lean Manufacturing in his work entitled "Value Stream Design: The Way Towards a Lean Factory, Springer Science \& Business Media, 2012, pg. 232". The researcher, Klaus Erlach [8], mentions that the purpose of this tool is to identify and eliminate or reduce "waste" in the process, thus improving the efficiency of the entire system. The disposal of "waste" is intended to improve productivity by creating a clearer process that will make "waste" easier to identify. We would say that it represents the systematized "radiography" of the entire process within a company, starting from the moment the customer issues an order and going until the moment the customer receives the ordered product. The aim is to determine the flow of materials and information that add value to the product.

Basically, in Value Stream Design we identify the activities with added value and those without added value within the process of creating the product/service offered to the final customer. It should be noted, however, that the level at which action is taken is the macro level and the details of the processes do not appear in the VSM. An important aspect of the VSM implementation process is the accuracy of the information underlying the mapping.

This information must be consistent with the actual situation to have a real "radiography" of the situation we are in at the end. This visual tool was developed by Toyota, to consider all the activities performed to 'manufacture' the product. or the service requested by the customer and to view the flow of materials and information in the analyzed area. In this way, losses can be identified in the value stream for which solutions are sought to reduce or eliminate them.

\section{Case study: optimization of the testing \& validation activities inside an automotive parts factory}

\subsection{The objective}

In this case study, it is proposed to analyze the functioning of the Testing / Validation Department (Fig. 1) in a factory that produces products for the automotive industry. Within the Department to be analyzed, the aim is to make the components according to the specifications ("Work request") and their resistance to wear over time, made in the local factory but also of other components produced by other "sister" factories in other countries. 


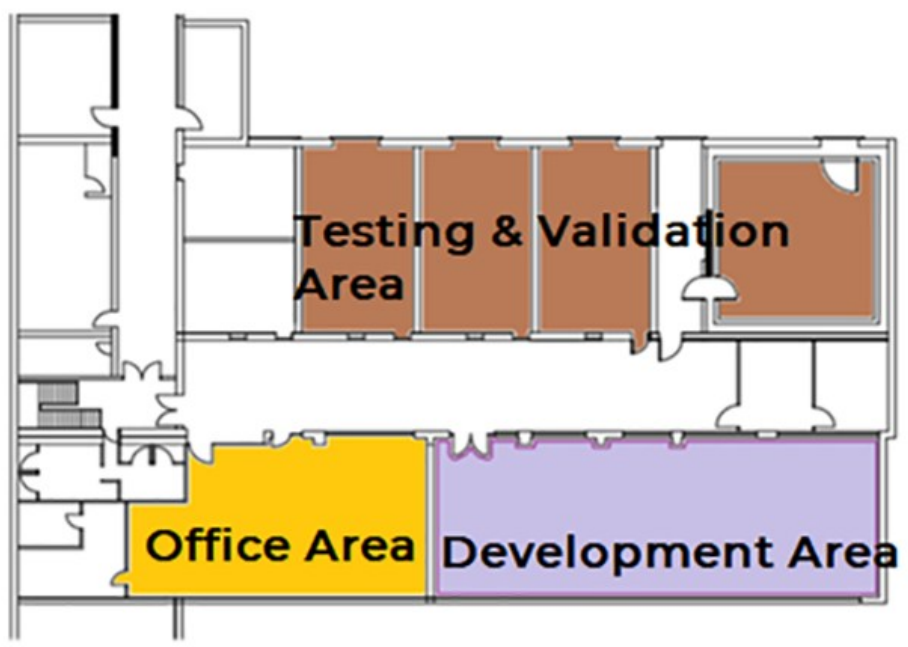

Fig. 1. The sketch of the testing/validation department.

\subsection{Defining the current situation}

Within the area where the Testing / Validation Department is located (Fig. 1), there is a similarity between the products (Table 1), more precisely, the fact that they are represented by certain tests. But these tests are different from each other. What makes them different can be found in the WR - Work Request. Here are recorded the values to be followed during the test but also requirements related to the mechanical setup, characteristics such as the value of pressure, temperature, and speed at certain key moments in the test, as well as specific information on data acquisition.

Table 1. Knowledge of the customer (supplier) and products.

\begin{tabular}{|c|c|}
\hline Products & Suppliers \& Clients \\
\hline $\begin{array}{l}\text { Test }+ \text { Report of the test for } \\
\text { Internal validation }\end{array}$ & UK Technical Centre \\
\hline $\begin{array}{l}\text { Test }+ \text { Report of the test for } \\
\text { phase } 3 \text { validation }\end{array}$ & Iasi Factory \\
\hline $\begin{array}{l}\text { Test + Report of the test for } \\
\text { Customer Return validation }\end{array}$ & \\
\hline $\begin{array}{l}\text { Test }+ \text { Report of the test for } \\
\text { Manufacturing Reliability } \\
\text { Assurance validation }\end{array}$ & \\
\hline $\begin{array}{l}\text { Test }+ \text { Report of the test for } \\
\text { Production Support validation }\end{array}$ & \\
\hline
\end{tabular}

Another element that makes the difference between the type of products is the type and order of tests required. Thus, a test requirement may consist of one or more single tests, which provide the validation engineer with the information necessary to label the tested component.

The second category (Table 1) is represented by the column of suppliers \& customers. They can be suppliers and/or customers both local (people from the Iasi Factory, maybe even from the same department - testing/validation) and external (people from "sister" companies, most often from technical centers in the UK - GTC, France - BTC). 


\subsection{Analyzing the current value stream map}

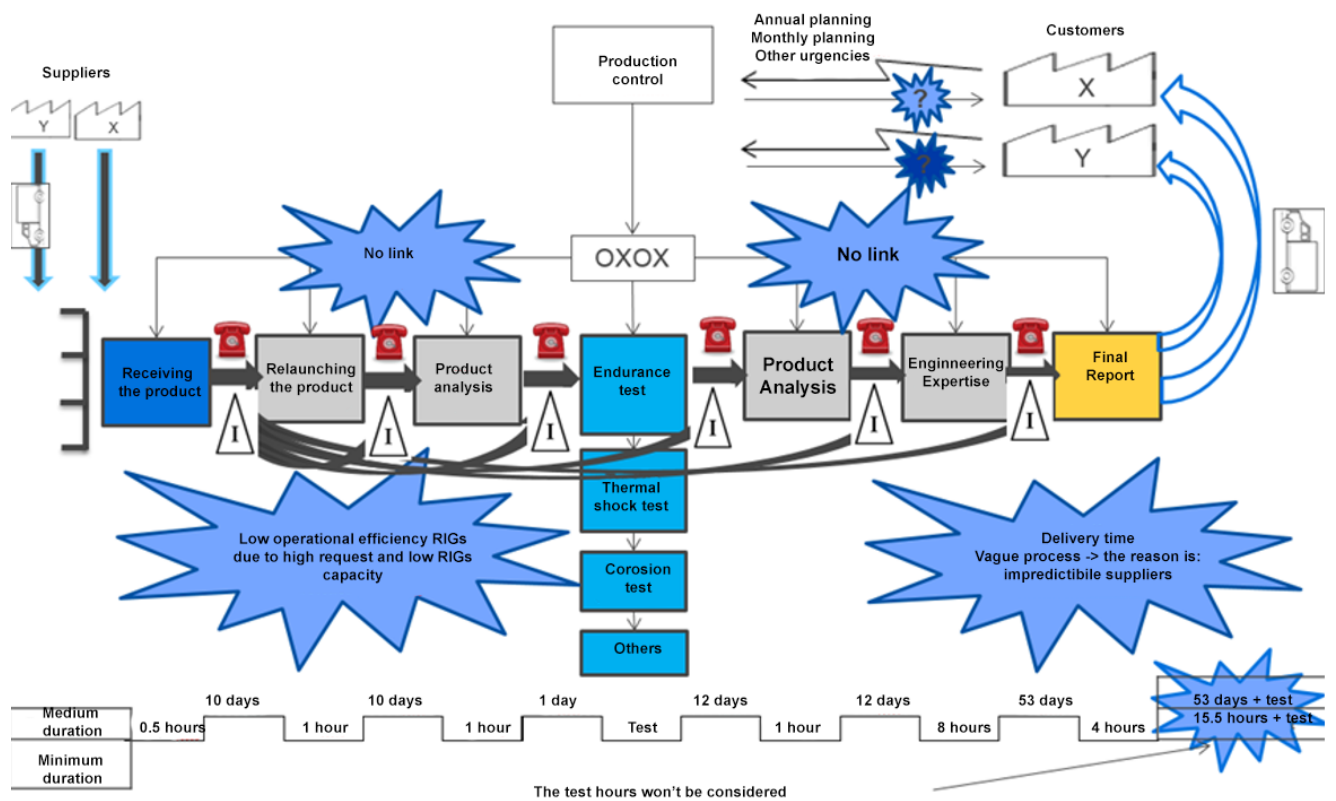

Fig. 2. Current value stream map.

It is thus observed the process that a product goes through (Fig.2), the time spent in each step but also the time spent between these steps:

1) Product receipt ( $1 / 2$ hour);

2) Waiting time until the next step - 10 days.

3) Product relaunch (1 hour);

4) Waiting time until the next step - 10 days.

5) Initial product characterization (1 hour);

6) Waiting time until the next step - 1 day.

7) Validation test - which can take various forms depending on the test requirement (duration differs depending on the test, and this duration is not intended to be reduced by this analysis);

8) Waiting time until the next step - 12 days.

9) Final product characterization (1 hour);

10) Waiting time until the next step - 12 days.

11) Expertise (8 hours);

12) Writing expertise report (4 hours);

13) Waiting time until the next step - 8 days.

14) Delivery back to Suppliers / Customers;

This analysis shows that the most time that the product spends in the Test / Validation Department is not time that brings added value because in this case, it is a dead time, waiting time between processes. 


\subsection{Analyzing the process and locating the bottleneck area}

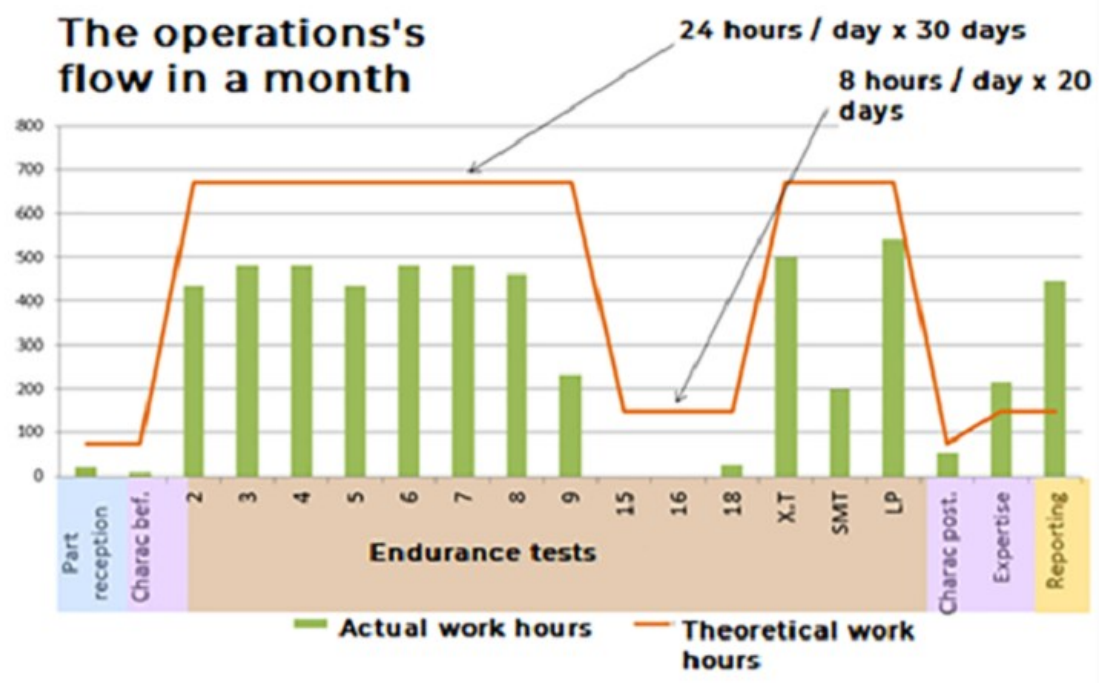

Fig. 3. The difference of operations - current working hours vs theoretical working hours.

The monthly reporting and the work schedule and the availability of employees ( 8 hours a day x 20 days) versus the operating schedule of the testing machines - this being non-stop (Fig.3), shows a considerate difference, justified by the discrepancy between the required workload vs. the workload done.

\subsection{Creating the ideal value stream map}

All losses discovered in the previous step will be eliminated through various projects or using specific Efficiency Maximizing System tools [4]. The new VSM should aim to eliminate at least $50 \%$ of the losses found in the analysis.

For the new VSM (Fig.4) it was decided to comply with the FIFO system for all steps in the process. According to the "first in - first out" method, the goods out of management are valued at the acquisition or production cost of the first entry (lot). As the lot is exhausted, the goods out of management are valued at the acquisition or production cost of the next lot, in chronological order.

Along with the FIFO method, the implementation of the Heijunka planning method, which will be reviewed monthly, which aims to level the production, to balance the cycle times specific to the different processes, has also been established.

The Heijunka is a traditional production planning methodology [10] for a repetitive mix of products or a family of products, aiming at leveling the load of the production station/line. The Heijunka box is a device (shelf, box, panel, etc.) used to level production, in terms of volume and variety of product types over a specified period. It is used as a means of visual control of production, using Kanban locations corresponding to customer orders. 


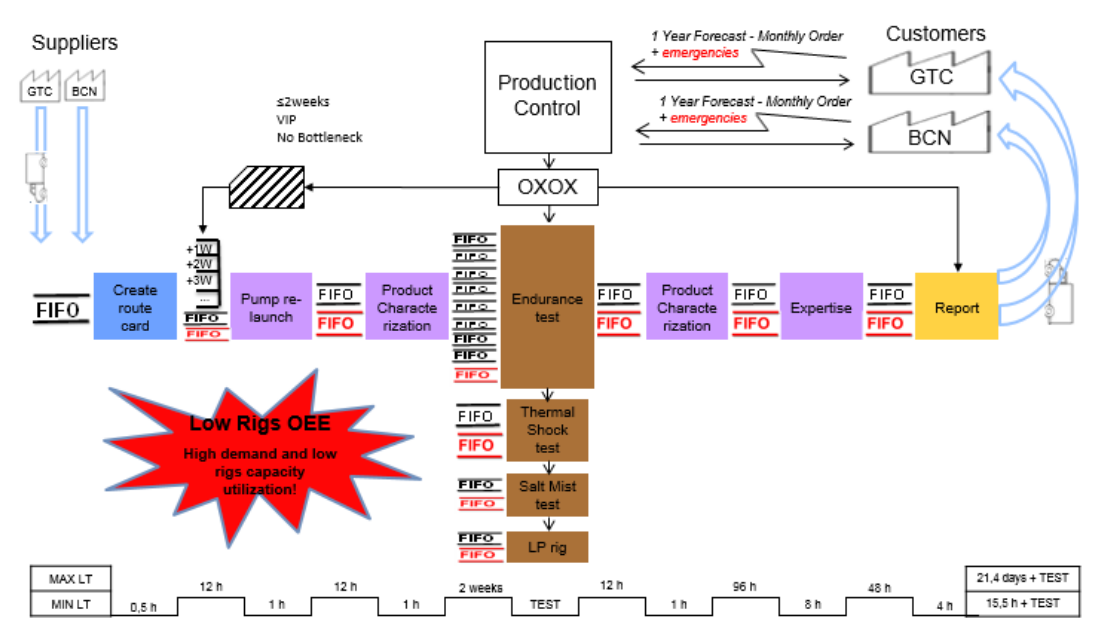

Fig. 4. The new Value Stream Map.

\subsection{Designing the new layout of the testing \& validation department}

Along with the application of the methods mentioned above, the time has come to reorganize the area of the Testing / Validation Department. It was thus decided that the central area of the area (Fig. 4) should be destined for FIFO where the products to be processed will be stored. The central area was carefully chosen for several reasons, including the fact that the distances from here are approximately the same in any direction.

Then, it was also noticed that the location of the products in the central area offers better visibility on the level of workload (Fig. 5) and saves us from downtime that would have been lost looking for a certain product in the whole area. This decision also shortened the average duration of a product in the Testing / Validation Department.

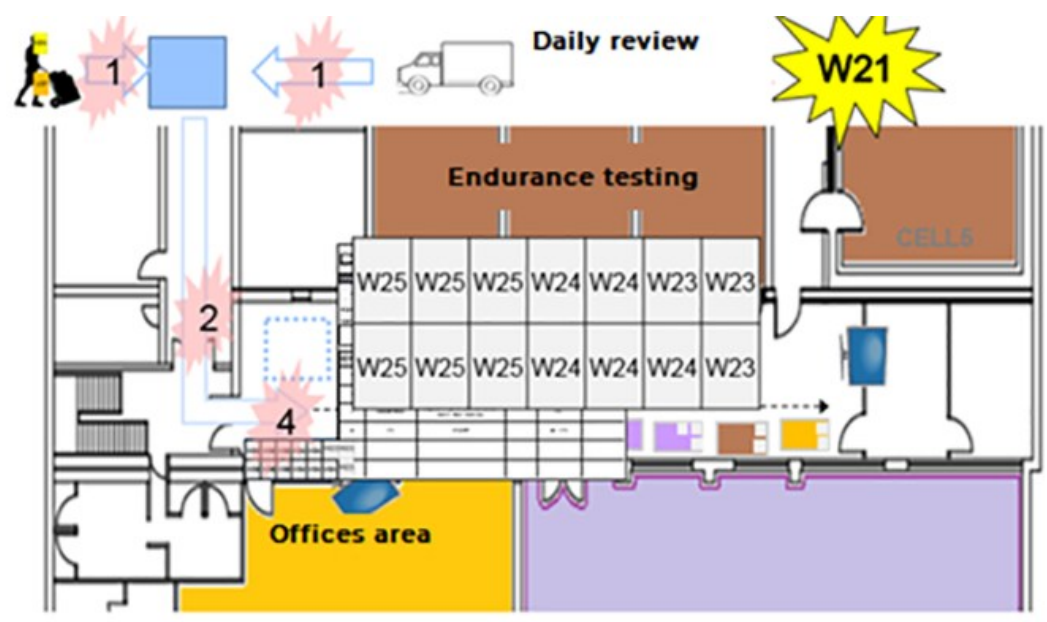

Fig.5. Reconfigured central area for FIFO style storage of products. 


\section{Conclusions}

The research performed shows that the application of the methods from the Lean methodology was a real success. Due to these methods, the quality of the activities in the Testing / Validation Department has been improved and, directly, the level of satisfaction of the clients/suppliers but also of the employees within the Department has increased.

After applying the above, it was possible to reduce the balance between the volume of work required and the volume of work performed (Fig. 6), the average duration spent by a product in this area was reduced (from 53 days + test duration to only 21 days). day + duration of the test - this is a discount of more than $50 \%$ ).

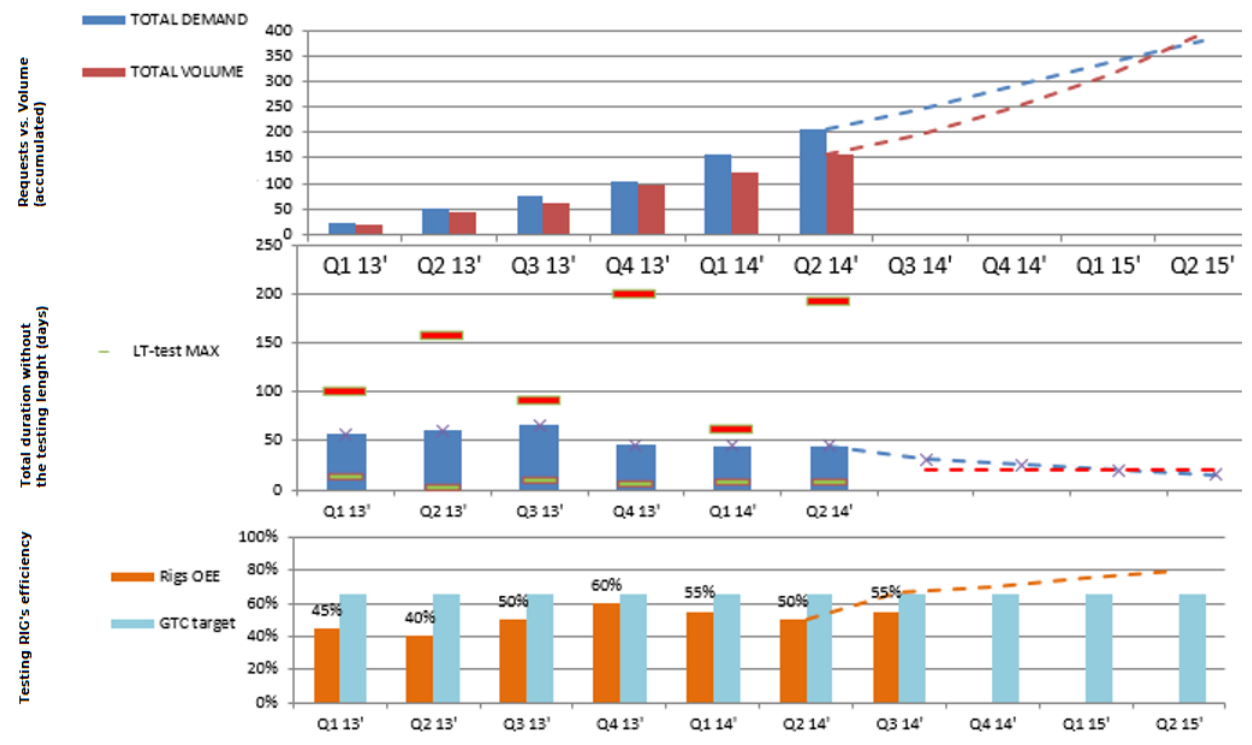

Fig. 6. The final balance between the required workload vs. the workload performed.

Also, by applying the methods of planning and approaching the workload, there has been both an increase in the workload that can be achieved, with the same resources as before, but also a reduction in the difference between the total requirements and the requirements that can be achieved. be realized. Directly, increased, and efficient running of testing machines.

According to the expression "all for one and one for all", the LEAN strategy does its best to promote safety, quality, standardization, cleanliness, staff training, respect, and maintaining the normal parameters of the activities carried out by the organization.

The LEAN organization system cannot and should not be precisely defined. There is no one right way, only one true answer. There is only one question: What are the real needs of the organization?

The only step we can take is to teach our team members the basics so that they can further develop them themselves.

\section{References}

1. M. B. Purushothaman, J. Seadon, D. Moore, J. Clean. Product., 265 (2020), Available: https://pubag.nal.usda.gov/catalog/6891020. [Accessed 12th November 2020] 
2. L.Steere, M.Rousseau, L.Durland, Journal of the Association for Vascular Access, 23,42-50 (2018)

3. P.Jadhav, N.Ekbote, Mater.Today:. Proc. (2021)[Online]. Available: https://wwwsciencedirect-com.am.e-nformation.ro/science/article/pii/S2214785320398473\#b0005. [Accessed 20th February 2021]

4. E.M.Villanueva, A.Couriel, O.O.Eshleman, D.E.Wilson, S.Varghese, T.Huerta, E.Barrera, O.Oriakhi, Research in Social and Administrative Pharmacy, 15, 38 (2019)

5. J.P Womack, D.T Jones, From Lean Production to the Lean Enterprise, Harvard Business Review, March-April (1994)

6. A.Kaufmann, G.Desbazeille, Metoda drumului critic (EdituraTehnică, Bucureşti, 1971)

7. Lean Manufacturing - metode de reducere a costurilor, Proiect pilot nr. RO/03/B/F/PP175017

[Online].

Available: www.smeskills.com/trainers/training/RO_MODUL $\% 205 \% 20 \% 20$ Metode $\% 20$ pentru $\% 2$ 0reducerea\%20costurilor\%20RO.pdf. [Accessed 10th November2020]

8. K. Erlach, Value Stream Design: The Way Towards a Lean Factory, Springer Science \& Business Media, Springer-Verlag Berlin and Heidelberg GmbH\& Co. KG, 232 (Dortmund, 2014)

9. N. J. Sayer, B. Williams, Lean For Dummies, 161 (John Wiley\& Sons, Hoboken NJ, 2011)

10. S. Gao, S.P. Low, Lean Construction Management: The Toyota Way, 195 (Springer, New York, 2014) 